\title{
Low Density Coarse coal Slime Separation with Teetered Bed Separator CHEN Youliang
}

\author{
Department of Chemistry and Chemical Engineering, \\ Xi'an University of Science and Technology, Xi'an 710054, China \\ youliangch@126.com
}

\begin{abstract}
Keywords: Column height; Separation zone; Coarse coal slime;
Abstract. The separation performance of the teetered bed separator for coarse coal slurry has been investigated. Experimental results show that the stability of the teeter bed has huge impact on separation efficiency. A number of data describe that the recovery of the separator involves both particle density and size. Therefore, heavy particles with large size have a big trendy to report to the overflow, and small coal grains with high density could easily sink to become the underflow product. It is found that it is of importance to select the tank, and both the column height and the teeter water velocity have significant influence and close relation with each other.
\end{abstract}

\section{Introduction}

The teetered bed separator is a kind of no secondary pollution of coarse coal slime separation equipment[1], which has extensively been investigated by numerous domestic and foreign researchers[2,3]. The principle of work and the characteristics of particle motion have been developed[4]. The physical properties and the motion characteristics of the interacted particles are always changed, thus affecting the particle size and density distribution and velocity distribution. Because of the bed media, the teeter currents and the gravity itself, most of the particles will move into the different directions. The particle will go up when the average density of the particles is below the density of the bed. However, while the average density of the particle is higher than the bed density, the particle will sink[5,6]. Meanwhile, a part of the particles could be suspended and formed into a bed layer[7,8]. The coal slurry in motion needs to overcome a series of friction not only between particles and equipment walls but also between grains of coal each other. In other words, stratification could be obtained by autogenous media and the teeter rising water, and various products could be gained and impacted by main teetered rising water. Statistically completed experiments were carried out to focus on the effect of the process variables on separation accuracy. The teetered bed separator with tubes was developed by Liu[9]. They found that the better separation efficiency was obtained to deal with coarse slurry with the narrow size composition or the high ash. Unfortunately, the tube-type device failed to treat the feed with a wide size distribution. The separator with damping blocks and pulsed currents was manufactured by Jiao[10]. There were better experimental results than the traditional technology, especially for a wide size distribution.

\section{Bed Density}

The bed pressure drop is mainly determined by the bed height, the suspension density and the porosity. And the bed porosity is influenced by the shape of the solid particle, the teeter water velocity and the size and density distribution. The bed density is controlled by the valve of the underflow to change the bed height and the particle distribution. If the interference bed is unstable in the coarse slime teetered bed separator, the separation performance will be not good. The larger the bed pressure drop is, the more the fine particles with high density into the overflow is.

\section{Material and Methodology}

A schematic representation is shown in Figure 1. The feed will stratify under autogenous media bed, the teeter water and gravity in itself. The particles with low density and coarse size enter into the upwards, while the other sink in the bottom and discharge through the valve. The separation process 
involves layering and separating. The main driving force of layering comes from media, while the force of separating is from the teeter water.

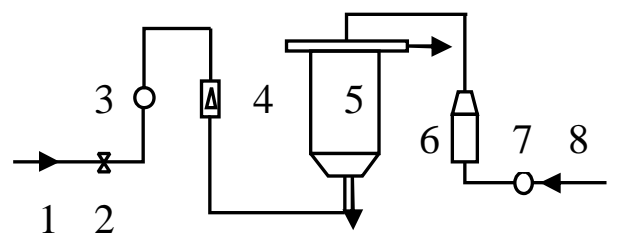

Fig.1 Schematic diagram of the experimental apparatus

1.Teeter water flow; 2.Water valve; 3.Pressure gauge; 4.Meter;

5.Teeter bed; 6.Classifying cyclone; 7.Manometer; 8.Feed

The coking coal sample between $0.3 \mathrm{~mm}$ and $2 \mathrm{~mm}$ is from Gujiao Coal Preparation Plant. The particle size analysis of the fine coal feed is shown in table 1. Every size fraction except the size varying from $0.45 \mathrm{~mm}$ to $0.8 \mathrm{~mm}$ contains approximately $15 \%$ with the different ash less than 5 percentage points. The feed between $0.45 \mathrm{~mm}$ and $0.8 \mathrm{~mm}$ is slightly more than $30 \%$ with $17.41 \%$ ash content.

Table 1 Size analysis of 2-0.3mm fine coal from Gujiaoxiqu Coal Preparation Plant

\begin{tabular}{|c|c|c|c|c|}
\hline \multirow{2}{*}{$\begin{array}{c}\text { Particle size fraction } \\
(\mathrm{mm})\end{array}$} & \multicolumn{2}{|c|}{ Various fraction } & \multicolumn{2}{c|}{ Cumulative oversize } \\
\cline { 2 - 5 } & $\begin{array}{c}\text { Weight percentage } \\
(\%)\end{array}$ & $\begin{array}{c}\text { Ash } \\
(\%)\end{array}$ & $\begin{array}{c}\text { Weight percentage } \\
(\%)\end{array}$ & $\begin{array}{c}\text { Ash } \\
(\%)\end{array}$ \\
\hline $0.45-0.3$ & 12.50 & 14.40 & 12.50 & 14.40 \\
\hline $0.8-0.45$ & 31.39 & 17.41 & 43.89 & 16.55 \\
\hline $1-0.8$ & 13.36 & 18.41 & 57.25 & 16.99 \\
\hline $1.25-1$ & 14.50 & 19.44 & 71.75 & 17.48 \\
\hline $1.6-1.25$ & 17.38 & 15.18 & 89.13 & 17.03 \\
\hline $2-1.6$ & 10.87 & 18.04 & 100.00 & 17.14 \\
\hline Total & 100.00 & 17.14 & - & - \\
\hline
\end{tabular}

\section{Results and Discussion}

The cumulative particle size distribution curves of not only the feed but also the overflow and the underflow product are indicated in Fig.2.
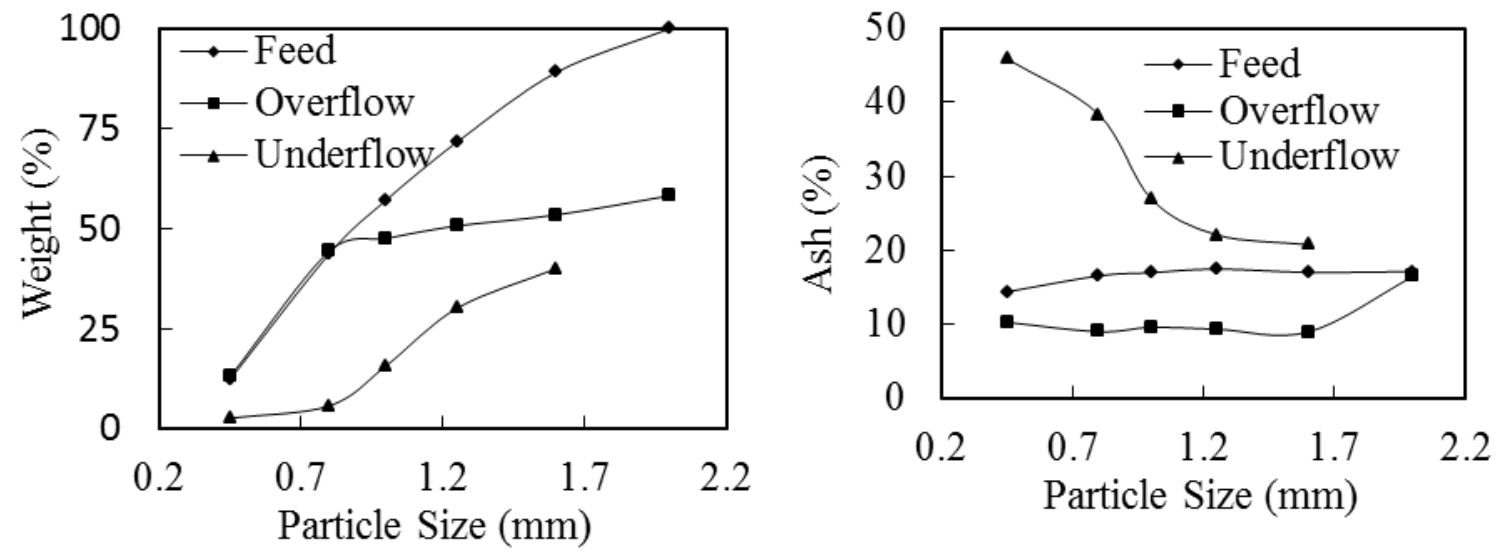

Fig.2 Cumulative particle size distribution curves Fig.3 Product ash curves

From Fig.2, it could be demonstrated that the particle sizes are uniformly distributed in the feed. Also, when the teeter water rate is $251 / \mathrm{min}$, there exists an obvious boundary which makes all particles divide into two parts in the separation column. The vast majority of the grains larger than $1 \mathrm{~mm}$ become the underflow tailing, while most grains less than $1 \mathrm{~mm}$ are sold as the overflow goods.

Fig. 2 indicates that an evident characteristic of the tailing is the larger size coal with lower density and the smaller size coal with higher density. The two experimental results fully explain the 
separation process is related with the particle size and density properties. From Fig.3, it is concluded that the ash of the underflow product gradually decreases because of the misplaced grains which have lower density and larger size.

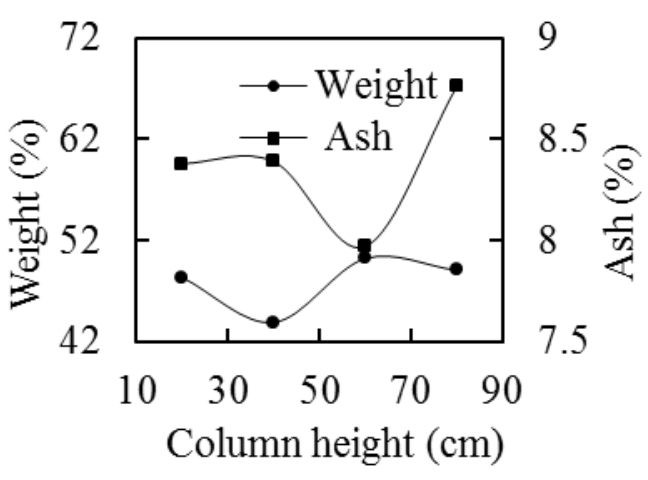

(a) $201 / \mathrm{min}$

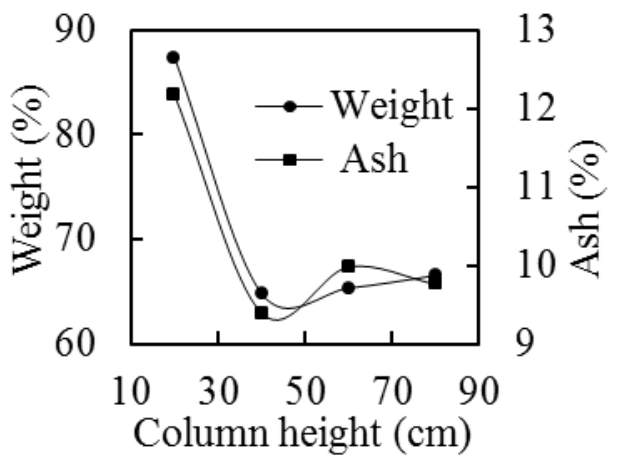

(c) $301 / \mathrm{min}$

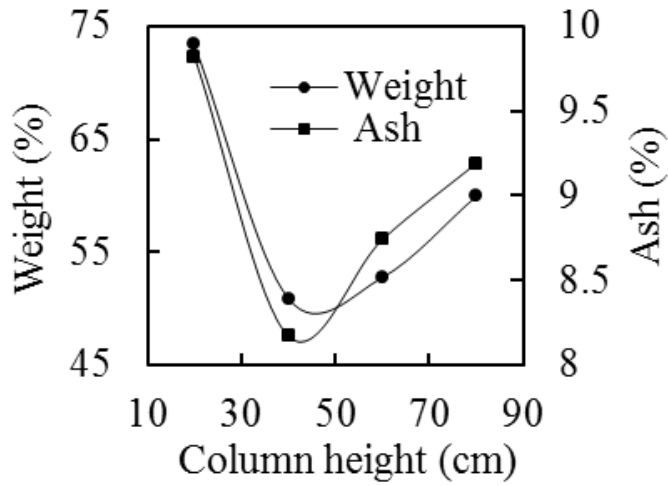

(b) $251 / \mathrm{min}$

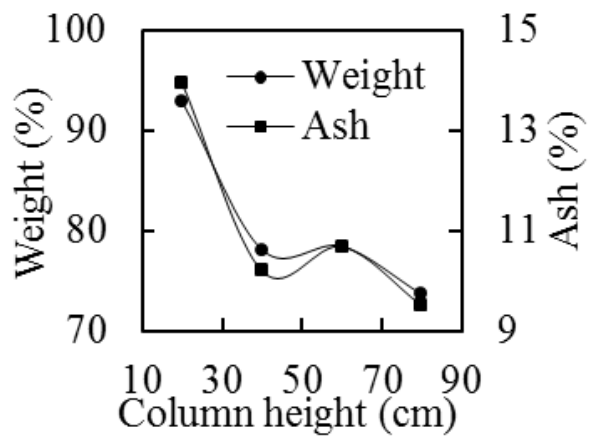

(d) $351 / \mathrm{min}$

Fig.4 The change of weight and ash of overflow products

Usually, there are five regions involving overflow zone, separation zone, bed zone, distribution plate zone and underflow zone in the teetered bed separator. The height of the tank mainly affects the size of the separation zone. It is noted that most of coal particles lower than the density of the bed density keep on layering and separating in the role of the teeter water in the separation part.

As shown in Figure 4(a), it is observed that for both product yields and ash, there are great changes with increasing column heights at the lower teeter currents. From these curves in Fig.4, at a higher water velocity the production ash and yields gradually decline with increase in the length of the tank. In the work process of the teetered bed separator, fine solid particles with heavy density are generally distributed in the lower part of the equipment. At the same time, in the upper part of them, the coal grains with coarse size and low density exist. When the flow rates enlarge to a certain extent, these two kinds of materials initially mix and are even separated again but reversed. Thus, too low water flow rate and column height result in larger misplacement of coal slurry particles.

The majority of the feed reports to the overflow resulting in no the formed suspension bed and no separation for all particles at too much lower column, as seen in Fig.4. The whole regions show high turbulence due to a higher water flow velocity and a smaller tank. At different height marked changes of both the rate of production and the ash are observed. Once the volume of the separation column is enough, the height effect is significantly reduced. Therefore, it may be the only importance for the size of the selection region and for the stability of the interference bed. It is necessary to explore the equipment performance together as the close relationship between column height and water rate.

As seen in Figure 5 and Figure 6, the yields and ash of the overflow products are compared to that of the underflow ones for the experiments conducted using the different teeter water velocities. In the various teeter currents, the ash of the overflow do not change with the product quantity . 


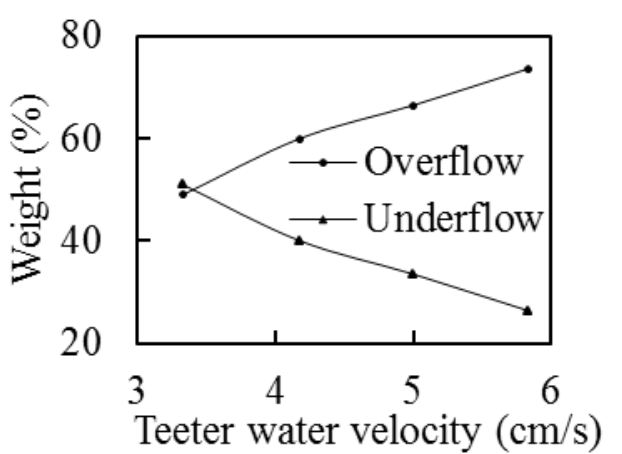

Fig.5 The change of product weights

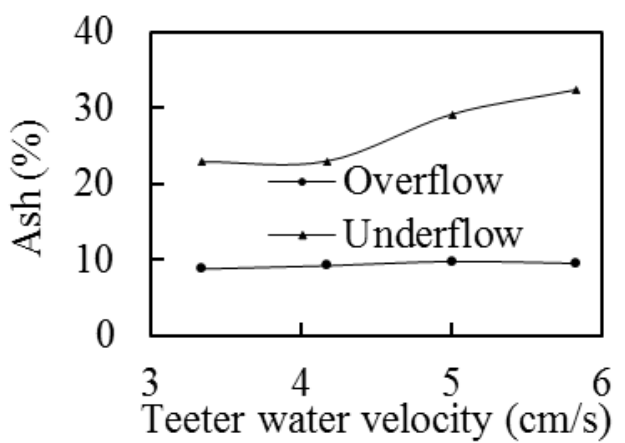

Fig. 6 The change of product ash

\section{Summary}

The teetered bed separator has been widely used in coal fields, and bought a technical reform in the coarse coal slurry recovery. The equipment bas board prospects because of no heavy media and chemical costs, floatation feed reduction and overall recovery improvement. The performance of the separator is closely related with the particle density and size distribution of the feed. The height of the column could be considered little influence if the separation zone assumed a sufficient height. The separation efficiency of the teetered bed separator would be surely improved by diminishing the height effect.

\section{References}

[1] K. P. Galvin, A. M. Callen, S. Spear, Gravity separation of coarse particles using the reflux classifier, Minerals Engineering23(2010)339 -349.

[2] X. Wang, Y. J. Tao, B. H. Wu, Research on application of teetered bed separator in Zhangshuanglou Coal Preparation Plant, China Mining Magazine24(2015)120-122.

[3] K. P. Galvin, K. Walton, J. Zhou, How to elutriate particles according to their density, Chemical Engineering Science(2009)2003-2010.

[4] R. B. Drummond, A. R. Swanson, S. K. Nicol, et al., Optimisation studies on a $75 \mathrm{t} / \mathrm{h}$ teetered bed separator at Stratford coal, XIII International Coal Preparation Congress, Australian Coal Preparation Society, Newcastle,(1999)198-204.

[5] Z. N. Wang, L. G. Tang, Separation characteristics of fine coal in hindered fluidized bed with perforated plate, Clean Coal Technology20(2014)64-67.

[6] X. N. Zhao, L. B. Wei, W. Lv, Feeding features affected to separation of Teetered Bed Separator (TBS), Coal Engineering(2013)102-104.

[7] S. L. Yang, A. M. Zhu, Feeding particle size and bedding density affected to separation effect of teeter bed separator, Coal Science and Technology40(2012)126-128.

[8] L. G. Tang, Experimental study on fine particle coal separation with disturbance bed assembled with inner parts, Coal Engineering(2012)103-105.

[9] W. L. Liu, Z. T. Chen, G. L. Wei, Study on law of coarse coal slime separation by hindered bed separator, Coal Preparation Technology(2007)11-13.

[10] H. G. Jiao, B. Hui, J. T. Feng, et al., Research on new teeter bed separation technology of coarse slime, Coal Engineering (2009)85-87. 